\title{
Fluid balance chart audit in a rural district general hospital
}

\author{
Authors: Oliver Cole ${ }^{\mathrm{A}}$ and Georgina White ${ }^{\mathrm{A}}$
}

\section{Background}

Fluid balance charts are an important monitoring document for patient safety and clinical care. The National Confidential Enquiry into Patient Outcome and Death report shows that inaccurate fluid balance monitoring impacts patient deaths in the perioperative period. ${ }^{1}$

Aims

Our audit aimed to assess accuracy, completeness and attitudes towards fluid balance charts including evidence of appropriate escalation when required.

\section{Methods}

This work is part of an ongoing audit conducted over an acute surgical and medical ward in a rural district general hospital. Two subsets of data were collected: questionnaire data on attitudes towards the fluid balance charts and a data set correlating bedside fluid charts with online electronic prescribing software and medical notes. Questionnaire data were collected over 5 days using paper questionnaires on the ward; 6 weeks later the second subset was collected using the physical fluid balance charts of 86 patients and we used an MS Excel tool to allow estimation and calculation of urine output.

\section{Results}

Despite high levels of confidence in using the charts, $68 \%$ of patients' fluid balance charts did not accurately match their electronic prescribing record. Questionnaire data corresponded to chart data subsets with questionnaires indicating $40 \%$ of respondents did not know the hourly urine output at which to escalate. Seventy-seven per cent of patients had at least 1 hour where urine output was $<30 \mathrm{~mL}$, concordantly $73 \%$ of patients who had a weight recorded had at least 2 hours where urine output $<0.5 \mathrm{~mL} / \mathrm{kg} / \mathrm{hr}$. However only $12 \%$ of patients had their urine output escalated in medical notes; $60 \%$ of patients had an input, output or balance recorded; of those who had an overall balance recorded, $90 \%$ were inaccurate.

\section{Conclusions}

This audit demonstrated very poor compliance with, and accuracy of, fluid balance charts. Dangerously low urine outputs were not

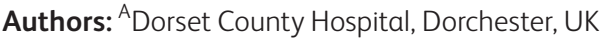

being escalated and acted upon. This has far reaching implications, not just for patient care but also for wider policy reviews given the pressurised ward environment becoming commonplace. Part of the problem is likely to be an excess of charts being used when no longer clinically indicated. Further education and changes to policy, attitudes and fluid balance chart design are required and ongoing. This includes formal teaching sessions, e-learning being developed, increasing ward awareness and potential policy changes including mandatory medical staff review of charts every $24-48 \mathrm{hrs}$.

\section{Conflicts of interest}

None declared.

\section{Reference}

1 National Confidential Enquiry into Patient Outcome and Death. Themes and recommendations common to all hospital specialties. London: NCEPOD, 2018. www.ncepod.org.uk/CommonThemes/ CommonThemes.pdf [Accessed 23 March 2019]. 